\title{
CONGENITAL ANOMALY IN 100 PREGNANT WOMEN IN A DISTRICT HOSPITAL OF BANGLADESH
}

\author{
BARUA HR ${ }^{1}$, BARUA RR ${ }^{2}, \mathrm{DHAR}_{\mathrm{SR}}^{3}, \mathrm{BARUA}^{4}$, BARUA AK ${ }^{5}$, PRASAD I ${ }^{6}$ ANSARI AJ ${ }^{7}$, \\ BEGUM K $^{8}$
}

\begin{abstract}
:
Background: Congenital anomalies are a major cause of stillbirths and neonatal mortality. The pattern and prevalence of congenital anomalies may vary over time or with geographical location.

Objective: To determine the types of congenital fetal abnormality and to find out the outcome of fetus.

Material and methods: One hundred cases of pregnant women with singleton pregnancy having congenital fetal anomaly were studied. The study was performed at the in-patient department of Obstetrics and Gynecology in Rangamati Medical College Hospital, Rangamati, Bangladesh from January 2016-December 2016. The newborn were examined for the presence of congenital anomalies and mothers were interviewed for socio-demographic variables.

Results: During the study period, it was observed that most of the women (63\%) belonged to age group between 21 and 30 years. More common congenital abnormalities were anencephaly (21\%), bilateral hydronephrosis (17\%), hydrocephalous (11\%) and ventriculomegaly (8\%). The deliveries were mostly (89\%) normal vaginal and the rest were caesarean section. Male fetuses are more prone to develop congenital abnormality. Congenital anomalies were more likely to be associated with still born, IUD, prematurity, multiparity, consanguinity and perinatal death.
\end{abstract}

Conclusion: Public awareness about preventable risk factors is to be created and early prenatal diagnosis and management of common anomalies is strongly recommended.

Key words: Congenital anomaly, Pregnancy

J Dhaka Med Coll. 2016; 25(2) : 105-109

\section{Introduction:}

A congenital anomaly is any structural (most common), functional, or biochemical abnormality that is present at birth ${ }^{1-2}$. The incidence of congenital anomalies is about $2 \%$ $5 \%$ at birth in India ${ }^{3}$.These anomalies are an important cause of neonatal mortality both in developed and developing countries. It accounts for $8 \%-15 \%$ of perinatal deaths and $13 \%-16 \%$ of neonatal deaths in India ${ }^{4-5}$. It is not only a leading cause of fetal loss but also contributes to preterm birth, childhood and adult morbidity along with considerable repercussion on the mothers and their families. Countries that have introduced the use of prenatal diagnostic techniques and access to termination of pregnancy due to congenital anomalies reduced neonatal mortality ${ }^{6-7}$.

1. Dr. Hena Rani Barua, Senior Consultant, Obstetric and Gynecology, Rangamati Medical College Hospital, Rangamati, Bangladesh.

2. Dr. Rita Rani Barua, Assistant Professor, Pathology, Dr. Sirajul Islam Medical College, Dhaka, Bangladesh.

3. Dr. Swapna Rani Dhar, Associate Professor, Obstetric and Gynecology, Dr. Sirajul Islam Medical College, Dhaka, Bangladesh.

4. Dr. Sushanta Barua, Indoor Medical Officer, Neuromedicine, Dhaka Medical College Hospital, Dhaka, Bangladesh.

5. Dr. Ajoy Kishore Barua, Medical Officer, Bandarban Sadar Hospital, Bandarban Hill District, Bangladesh.

6. Dr. Indrajit Prasad, Assistant Professor, Diabetes \& Endocrinology, Dhaka Medical College, Dhaka, Bangladesh.

7. Dr. M. Abdul Jalil Ansari, Professor, Diabetes \& Endocrinology, Dhaka Medical College, Dhaka, Bangladesh.

8. Kohinoor Begum, Professor, Obstetric and Gynecology, Popular Medical College, Dhaka, Bangladesh.

Correspondence: Dr. Hena Rani Barua, Senior Consultant, Obstetric and Gynecology, Rangamati Medical College Hospital, Rangamati, Bangladesh, Cell: +88-01818164056, E-mail:baruarita@yahoo.com.

Received: 07 July 2016

Accepted: 01 September 2016 
Most congenital anomalies are of multifactorial that is combination of genetic and environmental. Many studies observed that congenital abnormalities are associated with maternal age, consanguineous marriage, maternal obesity, teratogenic drugs, nutritional deficiency such as folic acid and iodine, infection like TORCH and HIV. A variety of chemicals associated with occupation are potential to develop such adverse birth outcomes as congenital anomalies, stillbirth, low birth weight and prematurity ${ }^{8-9}$. However, no maternal survey regarding congenital anomalies in Bangladesh is available till date and a little is known about hospital based statistics. A good number of congenitally abnormal babies are delivered in Rangamati Medical College Hospital. Therefore; this research work will determine the types of congenital anomalous fetuses that help national registry in future.

\section{Materials and methods:}

This cross sectional descriptive study was carried out at Gynecology and Obstetrics department of Rangamati Medical College Hospital, Rangamati from January 2016 December 2016. A total of one hundred pregnant women who fulfilled the inclusion criteria were included. Multiple pregnancy and pregnancy with other medical disorders such as diabetes, heart diseases, pregnancy induced hypertension, preeclampsia were excluded. All the congenital anomalous neonates, born in the department of Obstetrics and Gynecology during the study period either detected before birth by ultrasonogram of mother or detected at birth by the pediatrician and other appropriate investigations such as ultrasonography, radiography and echocardiography. After inclusion, detail relevant history was taken from the mother as well as from antenatal records, which included maternal age, gestational age, and previous history of delivery of congenital anomalous baby, sex and birth weight. Birth weights $>2.5 \mathrm{~kg}$ were considered to be normal; whereas, birth weights $<2.5 \mathrm{~kg}$ and $<1.5 \mathrm{~kg}$ were termed as low birth weight (LBW) and very low birth weight (VLBW) respectively. Babies born at $<37$ completed weeks were considered as premature. All anomalous babies were categorized at birth having major or minor anomaly by pediatrician. Immediate outcome of the baby whether the baby alive or dead was recorded. If the baby needed immediate management referred to neonatal unit. Data was entered into excel data sheet and appropriate statistical analysis was performed.

\section{Results:}

A total of 100 patients were included in this study. Maternal and fetal factors were shown in Table I.

Table I

Presentation of maternal and fetal factors $(n=100)$

\begin{tabular}{|c|c|c|}
\hline Mat & ernal factors & Percentage \\
\hline \multicolumn{3}{|c|}{ Maternal age (years) } \\
\hline 20 & 21 & 21 \\
\hline $21-25$ & 37 & 37 \\
\hline $26-30$ & 26 & 26 \\
\hline 31-35 & 16 & 16 \\
\hline \multirow{2}{*}{\multicolumn{3}{|c|}{$\begin{array}{l}\text { Mean } \pm \text { SD } \\
\text { Parity }\end{array}$}} \\
\hline & & \\
\hline Primi & 33 & 33 \\
\hline Multi & 67 & 67 \\
\hline \multicolumn{3}{|c|}{ Fetal outcome } \\
\hline Abortion & 53 & 53 \\
\hline IUD \& still birth & 19 & 19 \\
\hline Alive baby & 28 & 28 \\
\hline \multicolumn{3}{|l|}{ Mode of delivery } \\
\hline Vaginal delivery & 89 & 89 \\
\hline LUCS & 11 & 11 \\
\hline \multicolumn{3}{|l|}{ Fetal factors } \\
\hline \multicolumn{3}{|c|}{ Gestational age(weeks) } \\
\hline$<37$ & 76 & 76 \\
\hline 37 & 24 & 24 \\
\hline Mean \pm SD & $32 \pm 5$ & \\
\hline \multicolumn{3}{|c|}{ Gender distribution } \\
\hline Male & 53 & 53 \\
\hline Female & 47 & 47 \\
\hline \multicolumn{3}{|c|}{ Birth weight distribution } \\
\hline VLBW & 3 & 3 \\
\hline LBW & 18 & 18 \\
\hline Normal weight & 7 & 7 \\
\hline Total alive baby & 28 & 28 \\
\hline
\end{tabular}

Majority $(37 \%)$ of the patients belonged to 21 25 years of age group. The mean age was $25.27 \pm 5.2$ years and $67 \%$ were multipara. Maximum number of pregnant women (76\%) was found $<37$ weeks of gestation. The mean gestational age was $32 \pm 5$ weeks. Most of the fetus was delivered vaginally $(89 \%)$ and the rest $11 \%$ was cesarean section. In context of fetal outcomes, 53\% were abortion, 19\% still born and intra uterine death, and $28 \%$ were alive 
Table II

Distribution of congenital abnormality $(n=100)$

\begin{tabular}{lcc}
\hline Congenital anomaly & Number of patients & Percentage \\
\hline Anencephaly & 21 & $21 \%$ \\
Bilateral hydronephrosis & 17 & $17 \%$ \\
Hydrocephalous & 11 & $11 \%$ \\
Ventroculomegaly & 8 & $8 \%$ \\
Non-immune fetal hydrops & 6 & $6 \%$ \\
Omphalocele & 5 & $5 \%$ \\
Bilateral renal agenesis & 5 & $5 \%$ \\
Meningomyelocele & 5 & $5 \%$ \\
Achondroplasia & 3 & $3 \%$ \\
Bilateral pelvicalycealdilatation & 2 & $2 \%$ \\
Gastrosschisis & 2 & $2 \%$ \\
Dexocardia & 2 & $2 \%$ \\
Heart disease(ASD) & 2 & $2 \%$ \\
Microcephaly & 2 & $2 \%$ \\
Cardiomegaly with polycystic kidney disease & 1 & $1 \%$ \\
Absence of both limbs & 1 & $1 \%$ \\
Conjoint twin & 1 & $1 \%$ \\
Dilatation of lateral ventricle with meningocele & 1 & $1 \%$ \\
Omphalocele with ASD with VSD & 1 & $1 \%$ \\
Urinary bladder outlet obstruction & 1 & $1 \%$ \\
Ventroculomegaly with Telipes of foot & 1 & $1 \%$ \\
\hline
\end{tabular}

born. Regarding the distribution of congenital abnormalities; anencephaly was the commonest $(21 \%)$ followed by bilateral hydronephrosis $(17 \%)$, hydrocephalous $(11 \%)$, and ventriculomegaly (8\%) (Table II). More than a half $(53 \%)$ of the fetus was male. All the alive born neonates were admitted into neonatal ward and perinatal death was $23 \%$. Almost two third $(64 \%)$ of the new born had low birth weight (LBW), $3(10.7 \%)$ very low birth weight (VLBW) and $7(25 \%)$ had normal birth weight.

Anencephaly, Bilateral hydronephrosis, Hydrocephalous and Ventriculomegaly are common congenital anomalies

\section{Discussion:}

The pattern and prevalence of congenital anomalies may vary over time or with geographical location reflecting a complex interaction of known and unknown genetic and environmental factors including socio-cultural, racial and ethnic variables ${ }^{10}$. With improved control of infections and nutritional deficiency diseases, congenital malformations have become important causes of perinatal mortality in developing countries ${ }^{11}$.

With regard to pattern of congenital anomalies in the study, the most common anomaly was anencephaly $(21 \%)$, followed by bilateral hydronephrosis $(17 \%)$, hydrocephalous $(11 \%)$ and ventriculomegaly (8\%). Our neighbor country like India, the commonest congenital abnormality seen in musculoskeletal system $(33.2 \%)$, followed by gastro-intestinal tract (15\%), CNS $(11.2 \%)$, genitourinary $(10.5 \%)$, cardiovascular system $(9.1 \%)$, skin $(8.7 \%)$ etc ${ }^{12}$. Some studies recorded higher incidence of CNS malformations followed by GIT and musculoskeletal system whereas reported GI 
malformations as the most common one $\mathrm{e}^{3,13,14}$. These dissimilarities with our group may be due to genetic or environmental factors.

It is reported that a higher incidence of malformation in the babies born to mothers aged over 35 years $^{3,14}$. These were dissimilar with our research work where majority of malformed mother's age between 21-25 years. But the similar results of us were observed by other researchers ${ }^{15-16}$.

Previous studies have reported significantly higher incidence of malformations among the multipara and most of the pregnancy before 37 weeks of gestation ${ }^{16}$. This was consistent with present work which indicates a positive correlation between the birth order and the incidence of congenital anomalies. It was also noted that preterm babies were more prone to develop anomalies than full term ${ }^{17}$. It has been reported that significantly higher incidence of malformation among the mothers of gravida 4 or more which are consistent with the current study ${ }^{11,16}$. This indicates that as the birth order increases, the incidence of congenital anomalies also increases. The previous study evaluated the factors that significantly increased the risk of congenital malformations were hydramnions, maternal febrile illness in the first trimester, past history of abortions, diabetic mother, eclampsia, history of congenital heart disease in previous child or malformed babies etc.

In this study it was observed that $89 \%$ patients delivered normally and $11 \%$ underwent caesarean section. In Turkey, a five year retrospective regional study found $56 \%$ vaginal delivery and $44 \%$ caesarean section which was disimilar with the current study ${ }^{18}$. This might be due to we diagnose antenatally by USG and planned to deliver vaginally.

More male babies were born with congenital malformations than females which is consistent with other studies ${ }^{7,12,16,19-20}$. It may be because of the fact that the females were afflicted with more lethal congenital malformations and could not survive to be born with signs of life.
Association of LBW with increased risk of congenital malformations is very well documented $^{12}$. The incidence of congenital anomalies was significantly higher in preterm babies as compared with the full term babies, which was in conformity with the previous studies and ours ${ }^{12,16,21-22}$.

Despite the high risk of recurrence of congenital malformations, there are no well accepted preventive measures in developing countries like Bangladesh. It indicates that strong preventive measures for congenital anomalies in this region are needed. Increasing awareness about maternal care during pregnancy, educational programs on congenital malformations and the consequences of consanguineous marriages need to be highlighted to decrease the incidence of congenital anomalies and their comorbidity.

\section{Conclusion:}

This study has highlighted the types of congenital anomalies seen in our locality. Regular antenatal visits and prenatal diagnosis are recommended for prevention, early intervention and even planned termination, when needed.

\section{Conflict of interest: None}

\section{Acknowledgment:}

All the patients included in the study.

\section{References:}

1. Baird PA, Anderson, TW, Newcombe HB, Lowry RB. Genetic disorders in children and young adults: A population study. Am J Hum Genet 1988; 42: 677-93.

2. World health Organization. Section on congenital anomalies. Cited on 2012 Oct. Available from: http://www.who.int/mediacentre/factsheets / fs $370 /$ en $/$.

3. Dutta D.C. Hemorrhage in early pregnancy. Text book of Obstetrics $6^{\text {th }}$ ed. Konar, New central book agency Pvt Ltd; 2004: 159.

4. Bhat BV, Ravikumara M. Perinatal mortality in India need for introspection. Indian $\mathrm{J} \mathrm{MCH}$ 1996; 7: 31-3.

5. Agarwal SS, Singh PS, Das V, Sharma A. Prevalence and spectrum of congenital malformations in a prospective study at a teaching hospital. Indian J Med Res 1991; 94: 413-19. 
6. Watkins ML, Scanlon KS, Mulinare J, Khoury MJ. Is maternal obesity a risk factor for anencephaly and spina bifida? Epidemiol 1996; 7:5 07-512.

7. Golalipour MJ, Ahmadpour-Kacho M, Vakili MA. Congenital malformations at a referral hospital in Gorgan, Islamic Republic of Iran. EMHJ 2005; 4: 707-15.

8. Hemminki K, Mutanen P, Saloniemi I, Luoma K. Congenital malformations and maternal occupation in Finland: multivariate analysis. J Epidemiol community Health 1981; 35:5-10.

9. Shi L, Chia SE. A review of studies on maternal occupational exposures and birth defects, and the limitation associated with these studies. Occup Med (Lond) 2001;51:230-44.

10. Birch MR, Grayson N, Sullivan EA. AIHW Cat. No. PER 23. Birth Anomalies Serial No.1> Sydney: AIHW National Statistics Unot; 2004. Recommendations for development of a new Australian birth anomalies system: A review of the congenital malformations and birth defects data collection.

11. Mohanty C, Mishra OP, Das BK, Bhatia BD, Singh G. Congenital malformation in newborn: A study of 10,874 consecutive births. J Anat Soc India 1989;38:101-11.may not mention

12. Sarkar S, Patra C, Dasgupta MK, Nayek K, Karmakar PR. Prevalence of congenital anomalies in neonates and associated risk factors in a tertiary care hospital in Eastern India. J clin Neonatol 2013; 2:131-34.

13. Khatami F, Mamuri GH A. Survey of congenital major malformations in 10,000 newborns. Iran J Pediatr, 2005;15:315-20.
14. Suguna Bai NS, Mascarene M, Syamalan K, Nair PM. An etiological study of congenital malformation in the newborn. Indian Peditr 1982; 19:1003-7.

15. Shaw GM, Velie EM, Schaffer D. Risk of Neural tube defect-affected pregnancies among obese women. JAMA 1996; 275:1093-6.

16. Taksande A, Vilhekar, K, Chaturvedi $P$, and Jain M. Congenital malformations at birth in central India: A rural medial college hospital based data. Indian J Hum Genet 2010; 16:159-63.

17. Mathur BC, karan S, Vijaya Devi KK. Congenital malformations in the newborn. Indian Padiatr 1975;12:179-83.

18. Tomatir AG, Demirhan H, Sorkun HC, Koksal A, Ozerdem F, Cilengir N. Major congenital anomalies: a five-year retrospective regional study in Turkey Genetics and Molecular Research 2009; 8:19-27.

19. Stevenson AC, Johnston HA, Stewart MI, Golding DR. Congenital malformations: A report of study of series of consecutive births in 24 centers. Bulletin of the world health organization 1996; 34 (Suppl):9-27.

20. Shamohamdi F, Ahadi MA. The survey of congenital malformations in live births in Taleghani hospital. Iran $\mathrm{J}$ Arak Univer Med sci 1997; 1: 23-9.

21. Parmar A, Rathod PS, Patel VS, Patel MS. A study of congenital anomalies in newborn. NJIRM 2010; $1: 13-7$.

22. Baruah J, Kusre G, Bora r. Pattern of gross congenital malformations in a tertiary hospital in Northeast India. Indian J Pediatr 2015; 82:91722 . 